\title{
La curación de la hepatitis C implica una disminución de la mortalidad global
}

The cure for hepatitis C involves a decrease in overall mortality

\section{Objetivo}

Evaluar la asociación entre la respuesta virológica sostenida y la mortalidad global en pacientes con infección crónica por el virus de la hepatitis $\mathrm{C}(\mathrm{VHC})$ y fibrosis hepática avanzada.

\section{Diseño, lugar y pacientes}

Estudio de cohorte multicéntrico realizado en centros de hepatología de Europa y Canadá. Incluyó pacientes infectados con VHC y fibrosis hepática avanzada o cirrosis que recibieron un tratamiento con Peg Interferón-ribavirina con la intención de curar la enfermedad entre 1990 y 2003. El seguimiento se extendió hasta 2010-2011.

\section{Factor pronóstico y medición de resultados principales}

El objetivo primario fue evaluar la mortalidad global en dos grupos: con y sin respuesta viral sostenida al tratamiento. van der Meer Adriaan J y col. JAMA 2012; 308(24):2584-2593.

\section{Resultados principales}

El estudio siguió a 530 pacientes por una media de 8,4 años. De estos, $192(36 \%)$ alcanzaron la curación. La tasa acumulada de mortalidad a diez años fue $8,9 \%$ [IC95\% 3,3\% a 14,5\%] para los que se curaron (13 pacientes fallecidos) versus $26 \%$ [IC95\% 20,2\% a $28,4 \%$ ] para los que no alcanzaron la respuesta viral sostenida $(p<0,001)$.

\section{Conclusiones}

Entre los pacientes con hepatitis C crónica y fibrosis hepática avanzada, la respuesta virológica sostenida a un tratamiento basado en interferón se asoció a una menor mortalidad por todas las causas.

Fuente de financiamiento: The Foundation for Liver and Gastrointestinal Research. Ninguno de los autores tuvo un conflicto de interés directamente relacionado con el estudio.

\section{Comentario}

La hepatitis $\mathrm{C}$ crónica es actualmente un problema de salud de gran envergadura, de hecho recientemente se estableció por la OMS un día mundial de la hepatitis. En el mismo sentido, se sabe además que el pico de incidencia de la hepatitis $C$ recién se alcanzará en algunos años más ${ }^{1}$.

La curación de la hepatitis C crónica correlaciona con una disminución significativa de la posibilidad de evolucionar a falla hepática y consecuentemente a requerir de trasplante hepáti$\mathrm{Co}^{2,3}$. Si bien pareciera una consecuencia esperable, hasta la fecha, no se había demostrado que la respuesta viral sostenida luego de un tratamiento basado en interferón se asocie a una disminución global de la mortalidad por todas las causas en estos pacientes.

Este grupo de trabajo internacional de reconocidos centros de hepatología a nivel mundial presenta los resultados de un seguimiento de casi diez años luego del tratamiento. No solo observaron una disminución global de mortalidad, también constataron una diferencia significativa entre ambos grupos de pacientes al comparar otros resultados como fallo hepático, aparición de hepatocarcinoma, mortalidad por causa hepática y requerimiento de trasplante hepático.

\section{Conclusiones del comentador}

Por primera vez se deja constancia de la disminución de la mortalidad para el grupo de pacientes que desarrollan una respuesta viral sostenida, la cual es cada vez más factible con el advenimiento de los antivirales directos.

Joaquin Solari [ Sección de Hepatología del Hospital Italiano de Buenos Aires. joaquin.solari@hospitalitaliano.org.ar ]

Solari, J. La curación de la hepatitis C implica una disminución de la mortalidad global. Evid Act Pract Ambul. Jul-Sep 2013;16(3):88. Comentado de: van der Meer J Adriaan, Veldt Bart J, Feld Jordan J et al. Association between sustained virological response and all-cause mortality among patients with chronic hepatitis C and advanced hepatic fibrosis. JAMA 2012;308 (24):2584-2593. PMID: 23268517.

\section{Referencias}

1.Davis GL, Alter MJ El-Serag H, Poynard T et al. Aging of hepatitis C virus infected persons in the United States: a multiple cohort model of HCV prevalence and disease progression. Gastroenterology, 2010; 138(2): 513-521.

2. Cardoso AC, Moucari R, Figuereido-Mendes C et al. Impact of Peg Interferon and ribavirin theraphy on hepatocelullar carcinoma: incidence and survival in hepatitis $C$ patients con advanced fibrosis. J hepatol 2010; 52(5): 652-657.

3. Morgan TR, Ghany MG, Kim HY et al. HALT-C Trial group. Outcome of sustained virological responders with histologically advanced chronic hepatitis C. Hepatology 2010; $52(3): 833-844$. 